\title{
BENIGN PROSTATIC HYPERPLASIA: WHO NEEDS SURGERY, WHO NEEDS DRUGS?
}

\author{
WG Staff, Consultant Urologist \\ Lancaster \& Kendal Hospitals
}

\section{WHO NEEDS SURGERY?}

Fifty per cent of men in western countries will develop prostatic hyperplasia. The clinical problems caused by this will range from the life-threatening (rare) to the trivial or non-existent. The size of the prostate does not correlate well with symptoms.

Surgery should always be considered for those suffering serious complications. The most common of these are acute and chronic retention, urinary tract infection, stones and persistent urethral bleeding.

Acute retention often seems to strike out of the blue; few patients who develop this are already on the surgical waiting list. All patients should be considered for surgery but those who are bed- or chairbound may be best left with a catheter.

In many patients acute retention of urine develops in the immediate postoperative period after orthopaedic or other surgery. Clearly their fitness for prostatectomy will have to take into account what their previous surgery has been: for example, it is not safe to put a patient into the lithotomy position immediately following a hip joint operation as dislocation may occur.

Chronic retention of urine is another important reason for operating. Whilst not all cases are in renal failure, we still see some that are. After slow decompresssion, an improvement in renal function should occur, although in a bad case this may take a long time. Operations can be undertaken when the renal function is normal or stable.

Repeated or chronic urinary infection is another reason for operation. In such cases it is vital to image the urinary tract, usually with a plain radiograph and ultrasound, or with an IVU, whichever seems to be the easiest and most convenient for the radiology department to perform. This is important as with repeated UTI in prostate cases we may, as well as picking up a high residual urine, pick up such complications as stones or a large bladder diverticulum.

Bleeding may occur from the prostate. Occasionally it is very severe, often in association with diagnostic cystoscopy. An emergency operation may be needed. Some men may experience frequent bleeding usually after micturation. Its rather unsavoury nature may lead to prostatectomy.

This leaves us with a large number of men who simply have symptoms of prostatism and it is to those cases we should address ourselves, particularly as alternative treatments are available these days. A good history is vital: there is no substitute. For many years prostatic symptoms have been classified into irritative and obstructive unfortunately patients do not usually fit neatly into these two groups. By and large obstructive symptoms interest surgeons and those with irritative symptoms should not unless associated with a high residual urine.

\begin{tabular}{|c|c|c|}
\hline obstructive symptoms & $\begin{array}{l}\text { hesitancy } \\
\text { poor flow }\end{array}$ & $\begin{array}{l}\text { both worse when } \\
\text { bladder "bursting" }\end{array}$ \\
\hline irrritative symptoms & $\begin{array}{c}\text { nocturia } \\
\text { frequency } \\
\text { urgency } \\
\text { urge incontinence }\end{array}$ & \\
\hline \multicolumn{3}{|c|}{ After-dribbling common to all symptons } \\
\hline
\end{tabular}

It is important to realise that prostatic symptoms are variable and many patients consult their GP with prostatism because something has happened to precipitate the making of an appointment. This is usually a temporary worsening of the symptoms which may have an inflammatory if not infective cause. These symptoms may subside rapidly with or without treatment and the patient is back to his acceptable former state. In any event, symptoms may very considerably from week to week, day to day and even hour to hour.

\section{Investigations of prostatism}

The vast majority of patients with sterile urine in whom no serious pathology is suspected, with a benign feel to the prostate, a low PSA and moderate symptoms of an obstructive or irritative nature, can be investigated without full imaging of the urinary tract. It is self-evident that in a patient with severe obstuctive symptoms, investigations are a waste of time: he requires surgery or some other form of treatment. Equally, those with trivial symptoms do not require investigation or treatment. The majority of patients do not fall into either of these two extremes. We are offering a service now in which we do a plain film (KUB) to exclude stones in the urinary tract or prostate. The urinary flow rate is measured at least twice during the visit and the residual urine measured, not by catheter, but by a small dedicated ultrasound machine. We find the results usually most informative and we have produced guidelines for interpretation of the results by GPs, who we hope will take advantage of this open access service for patients. These guidelines will be produced and distributed later in the year.

\section{SURGERY}

What should the patient expect? He should look forward to going into a specialised urological ward, with urologicallytrained nursing staff and a resident conversant with training in the speciality. Such luxuries are rarely possible. He will, however, most likely have a transurethral section of the prostate. If the prostate is large, an open procedure, preferably a retropubic prostatectomy, as first described by Terence Millin in 1945, will be carried out. The former is usually well-tolerated. Blood loss can be high if the prostate 
is very large or the operator inexperienced. TURP carries the risk of absorption of the irrigating fluid into the bloodstream (TUR syndrome). Retropubic prostatectomy can be very bloody - the only safe way to stop the bleeding is to complete the operation, ie securing the bleeding with sutures. This may be extremely difficult for the inexperienced (how did we ever learn?).

Mortality rates after prostatectomy are very low, especially considering the risk factors that most patients exhibit. Death after TUR is very rare, but invariably associated with a severe acute myocardial ischaemia within the first 48 hours after surgery. Indeed, TURP has come under suspicion in respect of later death from myocardial ischaemia ${ }^{(1)}$. Pulmonary embolism is exceptionally rare after TURP, but less rare after an open procedure.

Incontinence after prostatectomy is a worry for most patients - in expert hands, a needless worry. I can remember only two patients developing incontinence after TURP in 24 years as a consultant, and both were successfully operated on. A tempoary incontinence after open prostatectomy is occasionally seen, often taking a few weeks or months to resolve. Of course some patients with urge incontinence continue with the problem post-operatively, a reflection, perhaps, of bad case selection and inappropriate surgery.

Retrograde ejaculation occurs in $60 \%$ of patients - rather surprising, one might have expected $100 \%$ - and younger patients are warned about this. Impotence after surgery occurs without doubt, but so does an improved performance, although rarely. The incidence of impotence is a direct reflection of the time the patient and surgeon spend discussing the problem. At the end of the day, a wellperformed prostatectomy on a well-selected patient gives excellent results.

\section{DRUG TREATMENT}

Understandably, patients are anxious to avoid surgery if possible, and would like to consider the other options on offer, although men seem just as reluctant to take pills as to undergo surgery. Remedies such as pumpkin seed and cranberry juice are popular, and our department has promoted the use of homeopathic remedies in suitable cases. There are, however, two types of drug on offer which may be prescribed by medical practitioners for BPH. These are the 5-alpha reductase inhibitor, Finasteride, and several types of alphablockers.

\section{5-alpha reductase inhibitor}

The development of benign prostatic hyperplasia requires the active metabolite of testosterone, dihydrotestosterone. The enzyme 5-alpha reductase mediates the conversion of testosterone to dihydrotestosterone. Two iso-enzymes of 5alpha reductase have been discovered. Type II is found in the prostate, liver and skin. Within the prostate the enzyme activity is found in the stromal cells and appears to increase in the stroma of prostate-showing $\mathrm{BPH}$ compared to the normal. Finasteride is an inhibitor specific to the 5-alpha reductase type II iso-enzyme. In crude terminology, it is used to shrink the prostate. Large-scale trials would suggest that this is the case with a reduction of $20 \%$ prostate volume in one year. This may be associated with significant subjective improvement and with objective improvement, albeit not dramatic, in flow rates and voiding pressure. There are side effects, impotence having been reported variously between three and nineteen per cent, and it would be best avoided if the man's partner is infertile as it is excreted in the semen and may damage a foetus. (Female pharmacists have to handle the drug wearing gloves). From both the patient and doctor's point of view, the biggest drawback is the fact that the drug takes a long time to become effective. Once started, the drug should not be abandoned as a failure for at least nine months. If effective, the patient will have to continue to take the drug, and longterm side effects are not yet known.

\section{Alpha blockers}

These drugs were originally used for the treatment of hypertension and work by causing vasodilatation.

In 1976 Caine $^{(2)}$ introduced the use of alpha blockers in bladder outlet obstruction, as they reduce smooth muscle tone in the bladder neck, prostatic urethra, prostatic capsule and prostatic adenoma. A favourable response clinically is achieved in $70 \%$ of patients. It is true to say, however, that they have never been popular with urologists because of side effects which are mainly related to blood pressure lowering effects. Urologists are also generally fearful of prescribing them for patients (the majority) who are already taking a frightful number of cardiovascuiar drugs.

Lately several sub-types of alpha blockers have been identified using sophisticated pharmacological and molecular biological techniques. Recently an alpha-1 c-subtypeselective alpha-l blocker has been introduced, claiming to be therapeutically efficient in respect of prostatic symptoms without the blood pressure lowering side effects. It is noteworthy that the BNF lists similar side effects for this drug as for the earlier alpha-blockers.

\begin{tabular}{|llll|}
\hline SHORT ACTING & DOSE & FREQUENCY & TRADE NAME \\
\hline Prazosin & $500 \mu \mathrm{g}-2 \mathrm{mg}$ & $\mathrm{bd}$ & Hypovase \\
\hline Alfuzosin & $5 \mathrm{mcg}$ & bd & Xarral \\
\hline Indoracin & $20 \mathrm{mg}$ & bd & Doralese \\
\hline Terzosin & $1-10 \mathrm{mg}$ & daily & Hytrin \\
\hline Doxazosin & $1-8 \mathrm{mg}$ & daily & Cardura \\
\hline $\begin{array}{l}\text { Tamsulosin } \\
\text { (prostatic-specific, } \\
\text { no effect on BP is } \\
\text { claimed) }\end{array}$ & $1-8 \mathrm{mg}$ & daily & Flomax \\
\hline
\end{tabular}

Table-Alpha blockers

Alpha blockers have the advantage that the first prescription will be sufficient to determine whether the drug is beneficial to a particular patient.

My personal view is that alpha blockers and Finasteride are not complementary drugs. They have different indications. I suggest Finasteride to patients normally over 70 years of age, with large prostates whose symptoms are moderate, usually mainly irritative rather than obstructive. These patients are not requiring immediate surgery but are perhaps anxious to avoid surgery in the future and to get some relief if possible. (It must be remembered that deterioration in such patients is the exception, not the rule). I suggest alpha blockers in fit younger men with severe obstructive symptoms who require surgery but may have to wait. The recent introduction of the "prostatic specific" alpha blocker may extend these indications.

A brief mention must be made of alternative invasive or surgical techniques. A variety of gadgets has been introduced, made of plastic or metal, to be inserted into the prostatic urethra to keep it open. Complications of such techniques have provided good copy for editors of urological 
journals. Balloon dilatation of the prostate has been recommended. I can do no better than quote Professor Blandy: "The notion of forcibly dilating the prostate with a balloon occurred to Philip Syng Physick of Philadelphia, one of John Hunter's pupils. It is revived every 50 years or so but always proves a disappointment"(3).

Laser treatment of the prostate certainly works but has produced dense strictures of the prostatic urethra as anyone familiar with the mechanism by which the prostatic cavity epithelialises after surgery may have predicted.

In summary, therefore, operate on those who are suffering severe symptoms or complications. Wait and see, or try drugs, in the majority, perhaps aided by the reassurance of satisfactory flow rate studies. If you feel surgery is needed, send him to the surgeon with the longest waiting list - the surgeon will only operate if it is absolutely necessary. Remember prostate surgery will not help the old man with urge incontinence, a good flow and no residual urine.

\section{REFERENCES}

1 Seagrott V Mortality after prostatectomy: selection and surgical approach Lancet 1995;346:1521-24

2 Caine M, Pfau A, Perlberg S The use of alpha-adrenergic blockers in benign prostatic obstruction $\mathrm{Br} \mathrm{J}$ Urol 1976;48:255-263

3 Blandy J, Fowler, C Urology 2nd edition Blackwell Science 1996

\section{What the Doctor said}

He said it doesn't look good

he said it looks bad in fact real bad

he said I counted thirty-two of them on one lung before

I quit counting them

I said I'm glad I wouldn't want to know

about any more being there than that

he said are you a religious man do you kneel down

in forest groves and let yourself ask for help

when you come to a waterfall

mist blowing against your face and arms

do you stop and ask for understanding at those moments

I said not yet but I intend to start today

he said I'm real sorry he said

I wish I had some other kind of news to give you

I said Amen and he said something else

I didn't catch and not knowing what else to do

and not wanting him to have to repeat it

and me to have to fully digest it

I just looked at him

for a minute and he looked back it was then

I jumped up and shook hands with this man who'd just given me

something no one else on earth had ever given me

I may even have thanked him habit being so strong 
